\title{
Is Asking Questions on Rounds a Teachable Skill? [Response to Letter]
}

This article was published in the following Dove Press journal:

Advances in Medical Education and Practice

\author{
Helen M Shields (D) \\ James $\mathrm{P}$ Honan ${ }^{2}$ \\ Jeffrey D Goldsmith ${ }^{3}$ \\ Rachna Madan ${ }^{4}$ \\ Stephen R Pelletier ${ }^{5}$ \\ Christopher L Roy ${ }^{6}$ \\ Lindsey $\mathrm{CWu}^{7}$ \\ 'Division of Medical Communications \\ and Division of Gastroenterology, \\ Hepatology and Endoscopy, Brigham and \\ Women's Hospital and Harvard Medical \\ School, Boston, MA, USA; ${ }^{2}$ Harvard \\ Graduate School of Education, \\ Cambridge, MA, USA; ${ }^{3}$ Department of \\ Pathology, Boston Children's Hospital \\ and Harvard Medical School, Boston, MA, \\ USA; ${ }^{4}$ Department of Radiology, Brigham \\ and Women's Hospital and Harvard \\ Medical School, Boston, MA, USA; \\ ${ }^{5}$ Office of Educational Quality \\ Improvement, Harvard Medical School, \\ Boston, MA, USA; ${ }^{6}$ Department of \\ Medicine, Brigham and Women's Hospital \\ and Harvard Medical School, Boston, MA, \\ USA; ${ }^{7}$ Duke University School of \\ Medicine, Durham, NC, USA
}

Correspondence: Helen M Shields Brigham and Women's Hospital, Boston, MA, USA

$\mathrm{Tel}+\mid$ 6I7 678-6077

Email hmshields@bwh.harvard.edu

\section{Dear editor}

We appreciate the thoughtful, insightful and helpful comments and suggestions we received in the Letter to the Editor from Seung Min Han, Pylin Parkes and Susannah Wang from the Imperial College School of Medicine, Imperial College, London, United Kingdom, regarding our article "Is asking questions on rounds a teachable skill? A randomized controlled trial to increase attendings' asking questions."

We agree that in our future research into the use of questions on bedside rounds, we will utilize their excellent suggestion of audio-video recordings of attending bedside rounds to evaluate the alignment of the attendings' questions with the specific role of each team member.

We recognize that a participant's perception of whether rounds were "worthwhile" or "engaging" is likely multifactorial. It is, not only the number and types of questions asked, but also relevant factors such as tone of voice, humility, kindness, body language, and genuine curiosity that drive the ratings of "worthwhile" and "engaging" to be excellent rather than mediocre. In our one-hour interactive intervention program, Dr. James Honan modeled ideal collegial and collaborative behavior while teaching experimental group attendings to ask a wider variety and number of questions. ${ }^{1,2}$

We agree with Han, Parkes and Wang that the reasons why residents in the experimental group found rounds statistically significantly more "worthwhile", but not significantly more "engaging" are not clear from the residents' survey comments that we collected. In our future research, we will define these terms concisely and clearly so that the responses we obtain are more meaningful.

Han, Parkes and Wang refer to two verbatim quotes from our free text survey that we interpreted differently. In response to the question, "What would make morning rounds more vibrant, inclusive and high-yield?", residents who rated rounds more "worthwhile" and had rounded with the experimental group attendings noted in their free text verbatim answers that they wanted "Asking questions in a no pressure way, knowing that the attending won't judge incorrect answers" and " Open questions from students encouraged." We interpreted these experimental group residents' comments as asking for more of what they had seen and rated as "worthwhile" on their surveys, namely, that the experimental group attendings had learned to ask questions in a gentle, kind and low-fear factor manner from Dr. James Honan resulting in a collegial climate at the bedside. In addition, the experimental group attendings encouraged questions from the medical students, but 
unfortunately, the number of medical students overall was too small to include in our final analyses.

We look forward to further research into this important area of education at the bedside and will incorporate the excellent comments and suggestions of Han, Parkes and Wang to improve and clarify our research protocols and methods.

\section{Disclosure}

The authors have no conflicts of interest in this communication.

\section{References}

1. Shields HM, Honan JP, Goldsmith JD, et al. Is asking questions on rounds a teachable skill? A randomized controlled trial to increase attendings' asking questions. Adv Med Educ Pract. 2020;11:921-929. doi:10.2147/AMEP.S277008

2. Shields HM, Pelletier SR, Roy CL, Honan JP. Asking a variety of questions on walk rounds: a pilot study. J Gen Intern Med. 2018;33 (6):969-974. doi:10.1007/s11606-018-4381-2

Dove Medical Press encourages responsible, free and frank academic debate. The content of the Advances in Medical Education and Practice 'letters to the editor' section does not necessarily represent the views of Dove Medical Press, its officers, agents, employees, related entities or the Advances in Medical Education and Practice editors. While all reasonable steps have been taken to confirm the content of each letter, Dove Medical Press accepts no liability in respect of the content of any letter, nor is it responsible for the content and accuracy of any letter to the editor.

\section{Publish your work in this journal}

Advances in Medical Education and Practice is an international, peerreviewed, open access journal that aims to present and publish research on Medical Education covering medical, dental, nursing and allied health care professional education. The journal covers undergraduate education, postgraduate training and continuing medical education including emerging trends and innovative models linking education, research, and health care services. The manuscript management system is completely online and includes a very quick and fair peer-review system. Visit http://www.dovepress.com/testimonials.php to read real quotes from published authors. 